Thorax (1955), 10, 258.

\title{
PNEUMOTACHOGRAPHIC MEASUREMENT OF BREATHING CAPACITY
}

\author{
BY \\ R. J. SHEPHARD \\ From the R.A.F. Institute of Aviation Medicine, Farnborough
}

(RECEIVED FOR PUBLICATION APRIL 11, 1955)

The measurement of breathing capacity makes exacting demands upon the designer of respiratory apparatus, since it is necessary to record rapidly changing rates of flow reaching peak values of up to $500 \mathrm{l}$./ $\mathrm{min}$. without introducing sufficient resistance into the system to affect the performance of the subject. Further, if the apparatus is to be of value in clinical medicine, it should be reasonably portable and easily sterilized.

The principal methods at present are three, and none approach perfection. The Douglas bag (Wright, Yee, Filley, and Stranahan, 1949; McKerrow, 1953a) is often considered to be widely available, but special wide-necked bags and lowresistance valve boxes are needed if reliable results are to be attained. Further, the accuracy of the method is dependent on split-second timing of tap manipulations, and the final answer gives no information about the respiratory rate at which the measurement was made. The problem of sterilization can only be solved effectively by the use of small expendable bags (McKerrow, 1953a). The Tissot spirometer (Greifenstein, King, Latch, and Comroe, 1952) is cumbersome, and careful modification of the system is needed to give a low resistance at high rates of air flow. The inertia of the bell is considerable, and may produce errors of up to $10 \%$ in the volume recorded. The BenedictRoth apparatus is perhaps the most widely used (Hermannsen, 1933; Baldwin, Cournand, and Richards, 1948 ; Gilson and Hugh-Jones, 1949 ; Gray, Barnum, Mathieson, and Spies, 1950 ; Gaensler, 1951; Turner and McLean, 1951). However, the standard apparatus has problems of resistance and inertia, and even if it be accepted that these difficulties are overcome by the use of a cellulose-acetate bell (Bernstein, D'Silva, and Mendel, 1952) there remain the objections that inspired gas composition is changing continuously throughout the experiment, and adequate sterilization is very difficult to achieve. Both spirometer methods have the important advantage that respiratory rate is recorded, and with the Benedict-
Roth apparatus an attempt can be made to analyse other parameters such as the "fast vital capacity" (Kennedy, 1953 ; Bernstein, 1954), although the ink-writing spirometer pen is not well adapted to this purpose.

Since there are a number of important objections to each of the present methods of recording breathing capacity, there are good grounds for considering other forms of apparatus, and the present paper examines the possibility of using a pneumotachograph to measure the parameters of breathing capacity. The pneumotachograph is a compact piece of apparatus, is easily sterilized, and recordings can be made with a galvanometer of high natural frequency. Further, values are obtained for the rate of respiration and the velocity of air-flow, and these are of considerable interest in examining the theoretical background of the maximum breathing capacity and the fast vital capacity tests. The experiments now to be described consist of an analysis of the physical properties of the recording system, and repeated measurements of maximum breathing capacity and fast vital capacity in a group of seven normal subjects.

\section{The Pneumotachograph}

General Considerations.-The pneumotachograph is in simple terms a means of measuring gas velocity in terms of pressure differential across a small resistance, provided in the pneumotachograph used by a fine wire screen ( 400 mesh Monel gauze). It is usual to provide manifolds and pressure-equalizing chambers in the shape of truncated cones on either side of the screen. In the application of this apparatus to the measurement of breathing capacity, it is necessary to consider particularly water vapour and temperature effects, resistance to air flow, and linearity and speed of response of the recording system.

Water-VAPOUR AND Temperature. - If the apparatus is arranged to record the velocity of expiratory gas flow, within a very few breaths 


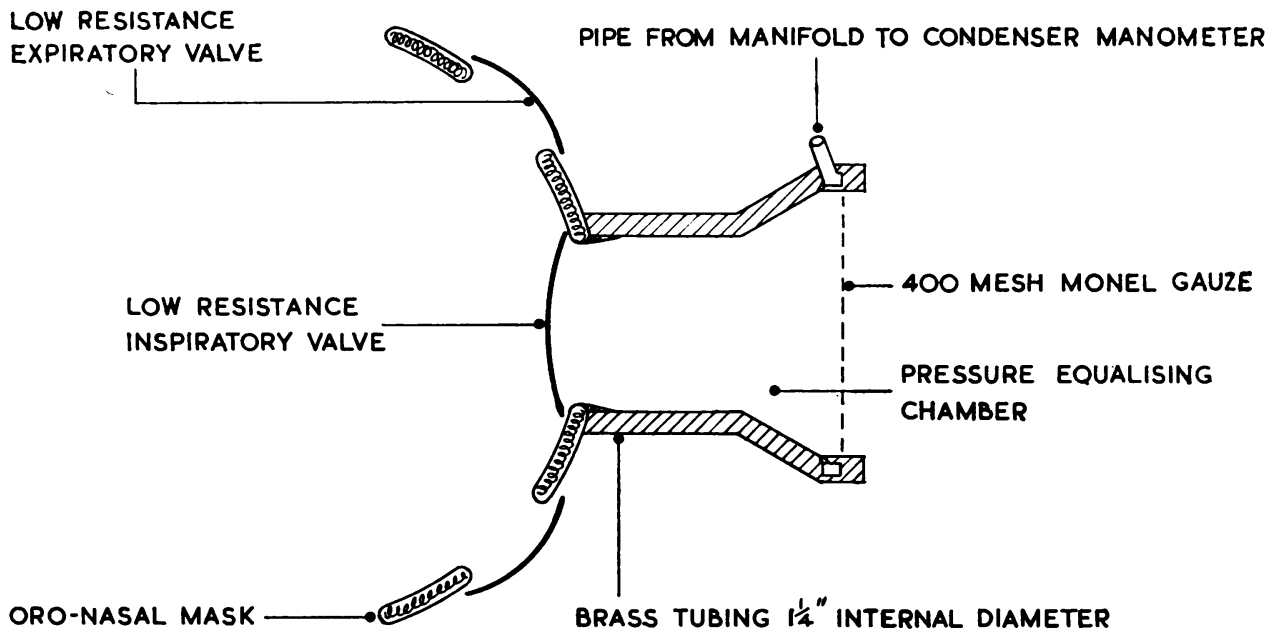

FIG. 1.-Modified pneumotachograph/mask assembly.

appreciable errors are caused by condensation of water-vapour in the mesh of the gauze. This difficulty can be overcome by the installation of a heater in the gauze mesh (Silverman and Whittenberger, 1950), but for clinical purposes it seemed simpler to record the breathing capacity in terms of inspiratory flow; it is unlikely that there is a significant difference between inspiratory and expiratory volumes at these high rates of flow. To record the fast expiratory vital capacity, the apparatus was blown through with compressed air between each reading to dry the gauze and restore the apparatus to room temperature. Observations with a thermocouple placed in the pneumotachograph at the level of the gauze showed that the rise of temperature during a forced expiration was of the order of 1 to $2^{\circ} \mathrm{C}$., and this would produce an error of well under $1 \%$ in the volume recorded.

Resistance To AIR-FLow.-Preliminary tests showed that the existing pneumotachograph had a rather high resistance at the rates of air-flow encountered in the maximum breathing capacity test. Since only inspiratory flows were to be recorded, it was decided to dispense with the distal pressure-equalizing chamber, exposing one aspect of the gauze direct to the atmosphere. The gauze itself introduced a resistance of no more than $5 \mathrm{~mm}$. water at a flow of $2501 . / \mathrm{min}$., so that little benefit could be expected from the substitution of a gauze of coarser mesh. However, it was possible to broaden the outflow from the proximal cone of the apparatus to an internal diameter of $1 \frac{1}{4}$ in., and lead this directly through a 2 in. length of tube to a low-resistance inspiratory valve and

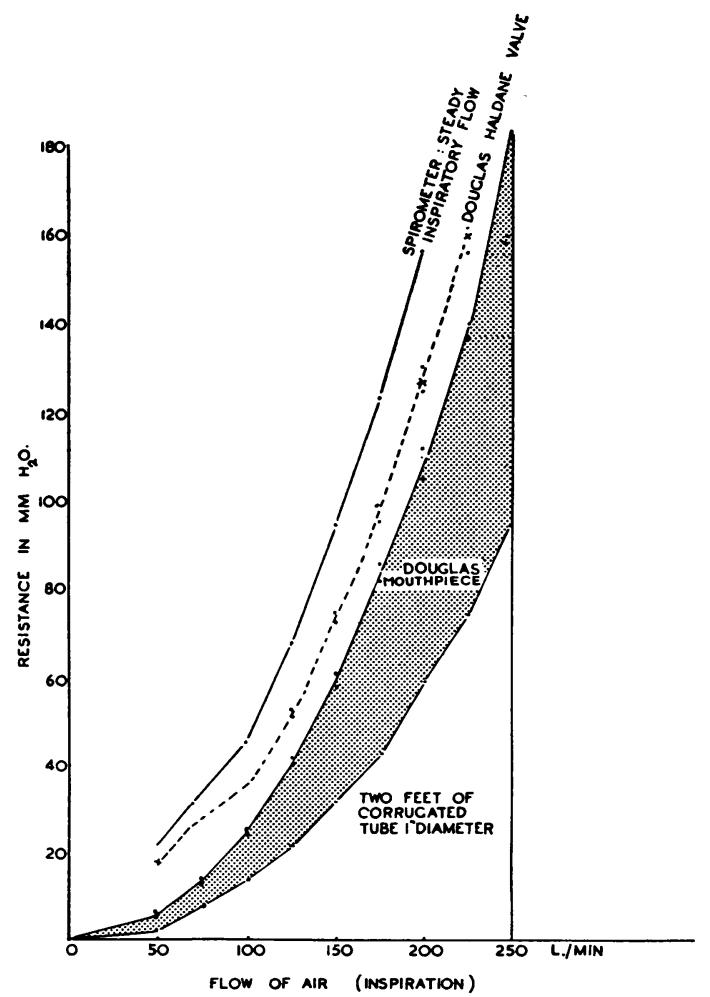

FIG. 2A.-Analysis of components contributing to total resistance of conventional Benedict-Roth spirometer system. The lowest curve represents the resistance of the tubing alone, the next the resistance of the tubing and mouthpiece, the third the resistance of tubing, mouthpiece and valve, and the top the resistance of the whole apparatus. 
moulded oro-nasal mask. The outflow from the mask was by two low-resistance valves direct to the atmosphere (Fig. 1). The resistance of this system was compared with that of the conventional spirometer with tubing and bivalved mouthpiece
Characteristics of Recording System.-A short length of pressure-tubing connected the manifold of the pressure-equalizing chamber to a condenser-manometer system (Southern Instruments Ltd., Camberley). The output of this

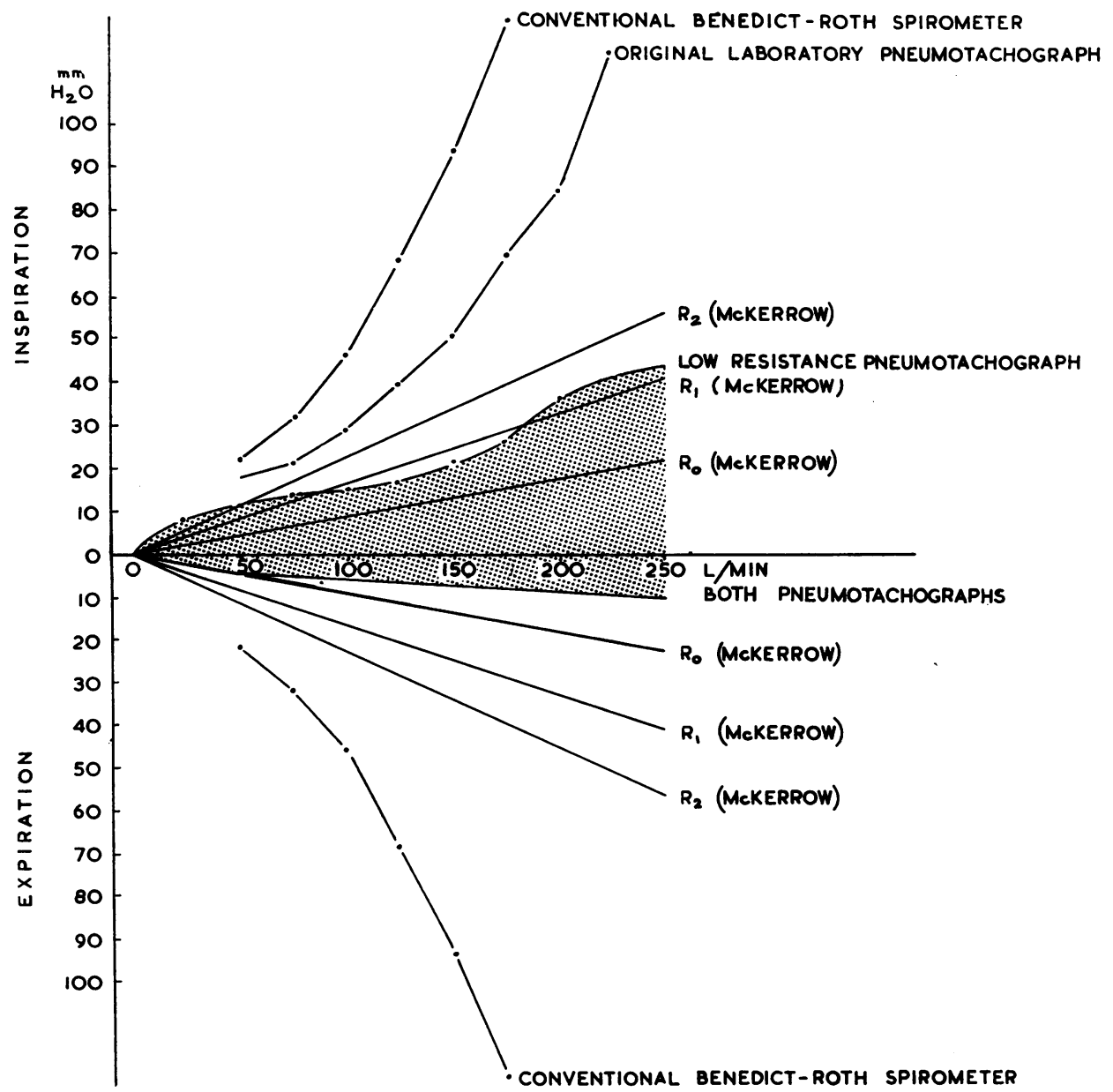

Fig. 2B.-Resistance of apparatus at different rates of inspiratory: and expiratory flow. The curve $\mathbf{R}_{0}$ indicates an ideal apparatus, $R_{1}$ produces no significant reduction of maximum breathing capacity, and $\mathbf{R}_{2}$ produces a significant reduction (McKerrow, 1953b).

(Fig. 2a) and with the data given by McKerrow (1953b) for various types of apparatus (Fig. 2b). During the expiratory phase the resistance was as low as any apparatus yet described. During inspiration the resistance was greater than that of McKerrow's “ideal" apparatus $\mathbf{R}_{0}$, but corresponded closely with the curve $R_{1}$ for an apparatus that produced no significant reduction of maximum breathing capacity. system after further smoothing was fed into a multi-channel bromide-paper recorder.

The response to a "step" change of flow was first examined, air being suddenly directed through the pneumotachograph by rotation of a three-way tap. A steady deflection without overshoot was reached in $100 \mathrm{~m} . \mathrm{sec}$., and since the time required was virtually independent of flow in the range $50-250 \mathrm{l} . / \mathrm{min}$. it seems reasonable to suggest that 


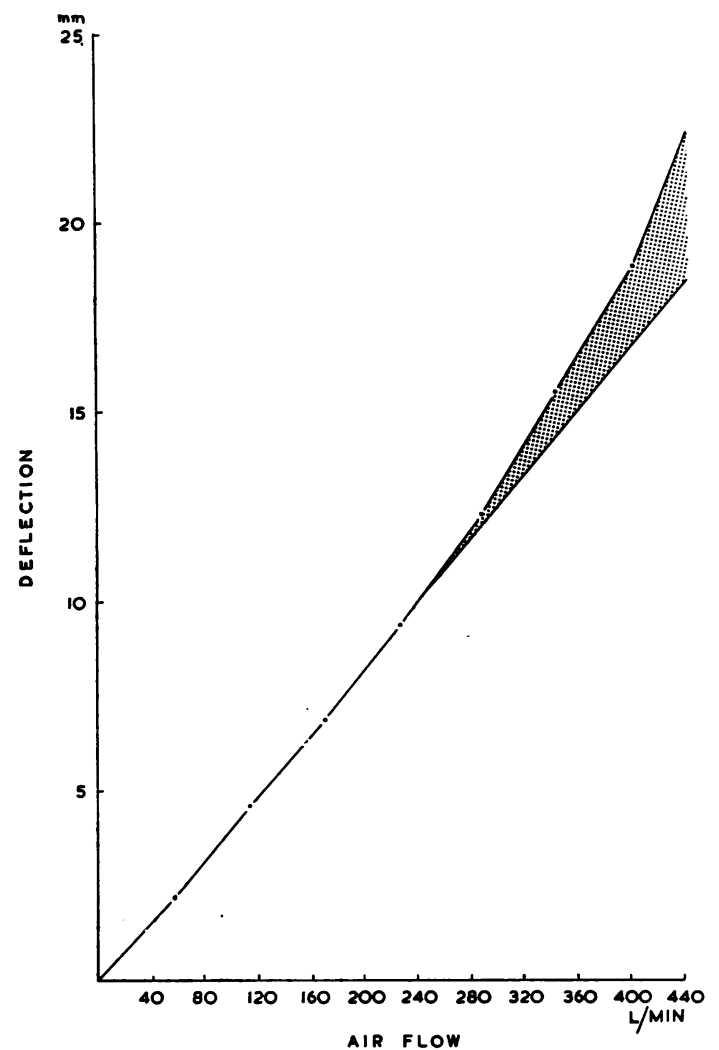

Fig. 3A.-Calibration curve for low resistance pneumotachograph. Note increasing departure from linear relationship above flow of $2401 . / \mathrm{min}$

much of this time lag was due to the period required to operate the tap.

The linearity of response was tested by comparing the galvanometer deflection with the flow as recorded by a sensitive air rotameter (Fig. 3a and b). In agreement with earlier work (Silverman and Whittenberger, 1950), the calibration curve shows good linearity up to a flow of $2401 . / \mathrm{min}$., but beyond this level the deflection for a given increase of flow becomes greater. Many normal subjects and most pathological subjects do not reach a higher average velocity than $240 \mathrm{l} . / \mathrm{min}$. during the maximum breathing test, but where this limit is exceeded it would be necessary to estimate the average inspiratory velocity during the test, and apply the appropriate correction for nonlinearity. In this way it is possible to extend the range of the apparatus to cover even the velocities encountered in very fit subjects.

INTEgRation of Tracings.-A planimeter was used to integrate respiratory minute volume. With practice two readings checking to within $1 \%$ could be obtained within ten minutes, comparing favourably with the time required to interpret a spirometer tracing or empty a Douglas bag.

FIG. 3. - Percentage deviation from linearity of calibration above flow rate of $2401 . / \mathrm{min}$

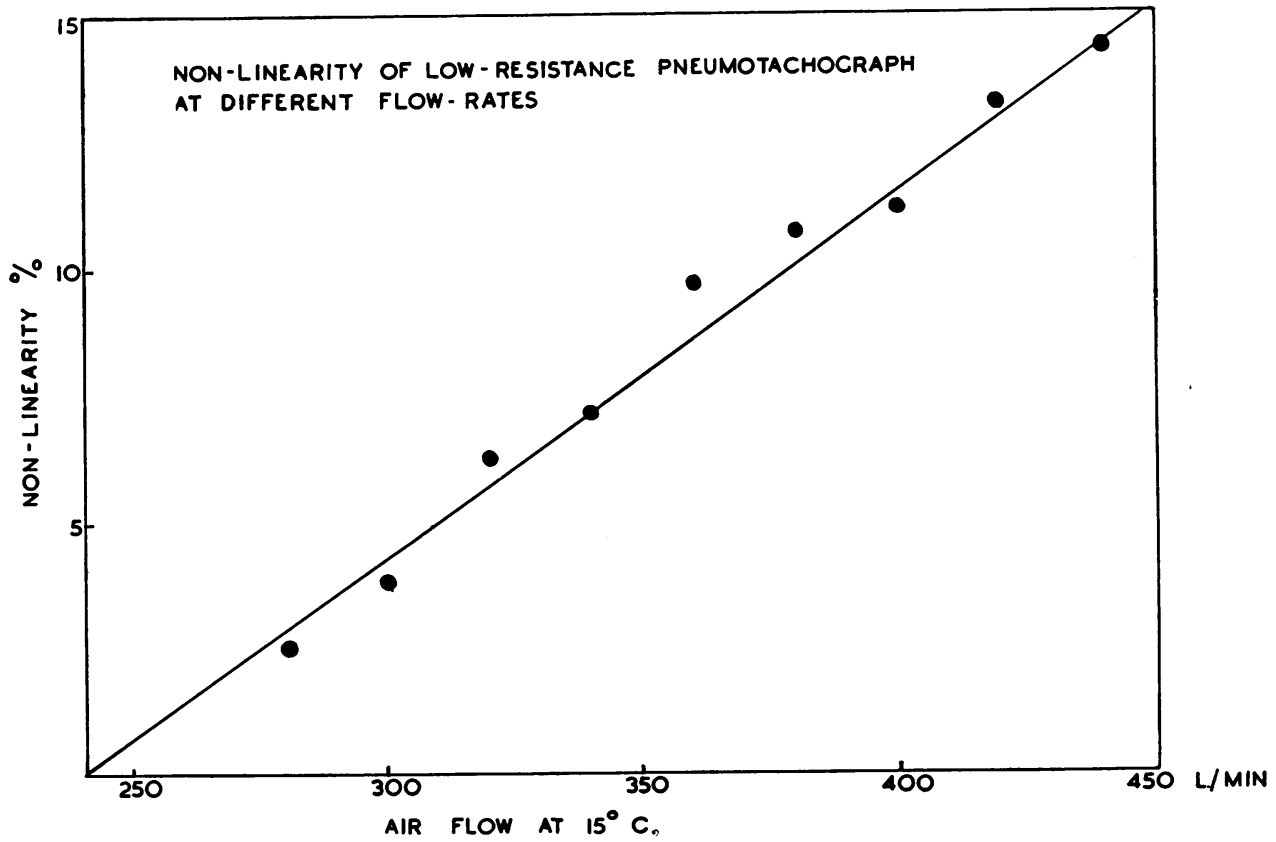




\section{The SubJects}

The subjects were all healthy, relatively young adults, members of the staff of the Institute of Aviation Medicine. Their physical characteristics and experience as respiratory subjects are detailed below :

\begin{tabular}{|c|c|c|c|c|c|c|c|c|}
\hline \multirow{2}{*}{ Subject } & \multirow{2}{*}{ Sex } & \multirow{2}{*}{$\begin{array}{c}\text { Age } \\
(\text { Yr. })\end{array}$} & \multicolumn{2}{|c|}{ Height } & \multicolumn{2}{|c|}{ Weight } & \multirow{2}{*}{$\begin{array}{c}\text { Body } \\
\text { Surface } \\
\text { (sq. m.) }\end{array}$} & \multirow{2}{*}{$\begin{array}{c}\text { Previous } \\
\text { Experience }\end{array}$} \\
\hline & & & (in.) & (cm.) & (lb.) & (kg.) & & \\
\hline $\begin{array}{l}\text { R. J. S. } \\
\text { D. P. } \\
\text { J. E. } \\
\text { P. B. } \\
\text { P. H. } \\
\text { V. B. } \\
\text { M. W. }\end{array}$ & $\begin{array}{l}\mathbf{M} \\
\mathbf{M} \\
\mathbf{M} \\
\mathbf{M} \\
\mathbf{M} \\
\mathbf{F} \\
\mathbf{M}\end{array}$ & $\begin{array}{l}25 \\
22 \\
26 \\
43 \\
29 \\
22 \\
26\end{array}$ & $\begin{array}{l}72 \\
68 \\
69 \\
68 \\
69 \\
57 \\
72 \frac{1}{2}\end{array}$ & $\begin{array}{l}182 \\
172 \\
175 \\
172 \\
175 \\
145 \\
184\end{array}$ & $\begin{array}{l}168 \\
160 \\
189 \\
176 \\
172 \\
118 \\
186\end{array}$ & $\begin{array}{l}76 \cdot 3 \\
72 \cdot 8 \\
85 \cdot 8 \\
79 \cdot 9 \\
78 \cdot 1 \\
53 \cdot 7 \\
84 \cdot 3\end{array}$ & $\begin{array}{l}1.97 \\
1.82 \\
2.02 \\
1.93 \\
1.92 \\
1.43 \\
2.08\end{array}$ & $\begin{array}{l}\text { Considerable } \\
\text { None } \\
\text { Considerable } \\
\text { None } \\
\text { Considerable } \\
\text { None } \\
\text { Fair }\end{array}$ \\
\hline
\end{tabular}

\section{The Maximum Breathing Capacity}

During preliminary trials, maximum breathing capacity observations were made with a number of types of apparatus, including a standard Douglas bag and mouthpiece, a standard Benedict-Roth spirometer, the original laboratory pneumotachograph, and an improved lowresistance pneumotachograph. The subjects were

TABLE I

TOTAL VENTILATION, AVERAGE RESPIRATORY RATE, AND AVERAGE PEAK INSPIRATORY FLOW DURING PERFORMANCE OF MAXIMUM BREATHING CAPACITY

\begin{tabular}{|c|c|c|c|c|}
\hline Subject and Method & $\begin{array}{l}\text { No. of } \\
\text { Obser- } \\
\text { vations }\end{array}$ & $\begin{array}{l}\text { Maximum } \\
\text { Breathing } \\
\text { Capacity } \\
\text { (I.'min. } \\
\text { B.T.P.S.) }\end{array}$ & $\begin{array}{c}\text { Rate } \\
\text { (per } \\
\text { min.) }\end{array}$ & $\begin{array}{l}\text { Average } \\
\text { Peak } \\
\text { Flow } \\
\text { (1./min. } \\
\text { B.T.P.S.) }\end{array}$ \\
\hline $\begin{array}{llll}\text { R. J. S. } & & \\
\text { Douglas bag } & . & \ldots & \ldots \\
\text { Spirometer } & \ldots & \ldots & \ldots \\
\text { Pneumotachograph } & \ldots & \\
\text { Improved pneumotachograph }\end{array}$ & $\begin{array}{l}2 \\
8 \\
3 \\
5\end{array}$ & $\begin{array}{r}97 \cdot 0 \\
116.7 \\
117.6 \\
143 \cdot 5\end{array}$ & $\begin{array}{l}52 \\
82 \\
74\end{array}$ & $\overline{248}$ \\
\hline 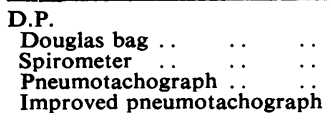 & $\begin{array}{l}1 \\
4 \\
3 \\
3\end{array}$ & $\begin{array}{l}121 \cdot 8 \\
126 \cdot 5 \\
117 \cdot 3 \\
111 \cdot 0\end{array}$ & $\begin{array}{r}\overline{45} \\
105 \\
72\end{array}$ & $\frac{\bar{z}}{230}$ \\
\hline $\begin{array}{l}\text { P. B. } \\
\text { Spirometer . } \ldots \\
\text { Pneumotachograph } \ldots \\
\text { Improved pneumotachograph }\end{array}$ & $\begin{array}{l}4 \\
3 \\
3\end{array}$ & $\begin{array}{l}106 \cdot 3 \\
106 \cdot 6 \\
102 \cdot 0\end{array}$ & $\begin{array}{l}38 \\
58 \\
68\end{array}$ & $\begin{array}{l}\overline{208} \\
217\end{array}$ \\
\hline $\begin{array}{l}\text { P. H. } \\
\text { Spirometer . . . . } \\
\text { Improved pneumotachograph }\end{array}$ & 2 & $\begin{array}{l}150 \\
184\end{array}$ & $\begin{array}{l}60 \\
99\end{array}$ & $\overline{365}$ \\
\hline $\begin{array}{l}\text { V. B. } \\
\text { Spirometer ... } \\
\text { Improved pneumotachograph }\end{array}$ & 2 & $\begin{array}{l}72 \cdot 6 \\
75 \cdot 9\end{array}$ & $\begin{array}{l}44 \\
42\end{array}$ & $\overrightarrow{179}$ \\
\hline $\begin{array}{l}\text { J. E. } \\
\text { Spirometer ... } \\
\text { Improved pneumotachograph }\end{array}$ & 2 & $\begin{array}{l}116 \\
166\end{array}$ & $\begin{array}{r}116 \\
88\end{array}$ & $\overline{380}$ \\
\hline $\begin{array}{l}\text { M. W. } \\
\text { Improved pneumotachograph }\end{array}$ & 2 & 152 & 75 & 383 \\
\hline $\begin{array}{l}\text { H. R. } \\
\text { Improved pneumotachograph }\end{array}$ & 1 & 146 & 62 & 320 \\
\hline
\end{tabular}

in the standing position in order to allow greater chest mobility, and after a 15 sec. preliminary period of normal breathing they were instructed to breathe as deeply and as rapidly as possible for 15 seconds. The results obtained are summarized in Table $I$.

There is fair agreement between the M.B.C. values recorded by the different methods, although in some subjects the pneumotachograph has given rather higher values than the spirometer. No evidence has been found of any systematic error leading to an over-estimate of the breathing capacity by the pneumotachograph method, and it therefore seems reasonable to accept these higher values as the true capacity of the subjects. The spirometer values are probably lower on account of the greater resistance of this apparatus, although this error is partly offset by resonance effects (Bernstein and others, 1952), since the respiratory rate is in most instances close to the natural frequency of the spirometer-water-jacket system. The two forms of pneumotachograph have been compared in three subjects, and in one (R. J. S.) a definite improvement in performance has resulted from the further reduction of resistance. The values obtained by the improved pneumotachograph agree well with data from other laboratories using low-resistance systems, and it seems fair to suggest that the pneumotachograph has a place in respiratory physiology as a convenient and accurate method of measuring the maximum breathing capacity.

It is also possible to follow the breath-by-breath performance with the pneumotachograph. Some of the present group of subjects were able to achieve a maximum effort with the first breath, but others despite a counted five-second warning of the start of the test took one or two breaths before reaching a maximum respiratory velocity and tidal volume (Fig. 4). Most subjects showed a slight deterioration of performance during the last five seconds of the test (particularly a fall of peak inspiratory velocity). Fatigue of this order was considered a useful sign that the subjects had in fact given of their best.

There is considerable personal variation in the choice of respiratory rate during the performance of the M.B.C. test. There also seems a systematic difference between the spirometer and pneumotachograph methods, subjects tending to adopt a slower respiratory rate when breathing into the spirometer. The rate with this form of apparatus is probably conditioned largely by the natural frequency of the system, since the resistance to respiration is lowest when the subject follows the 


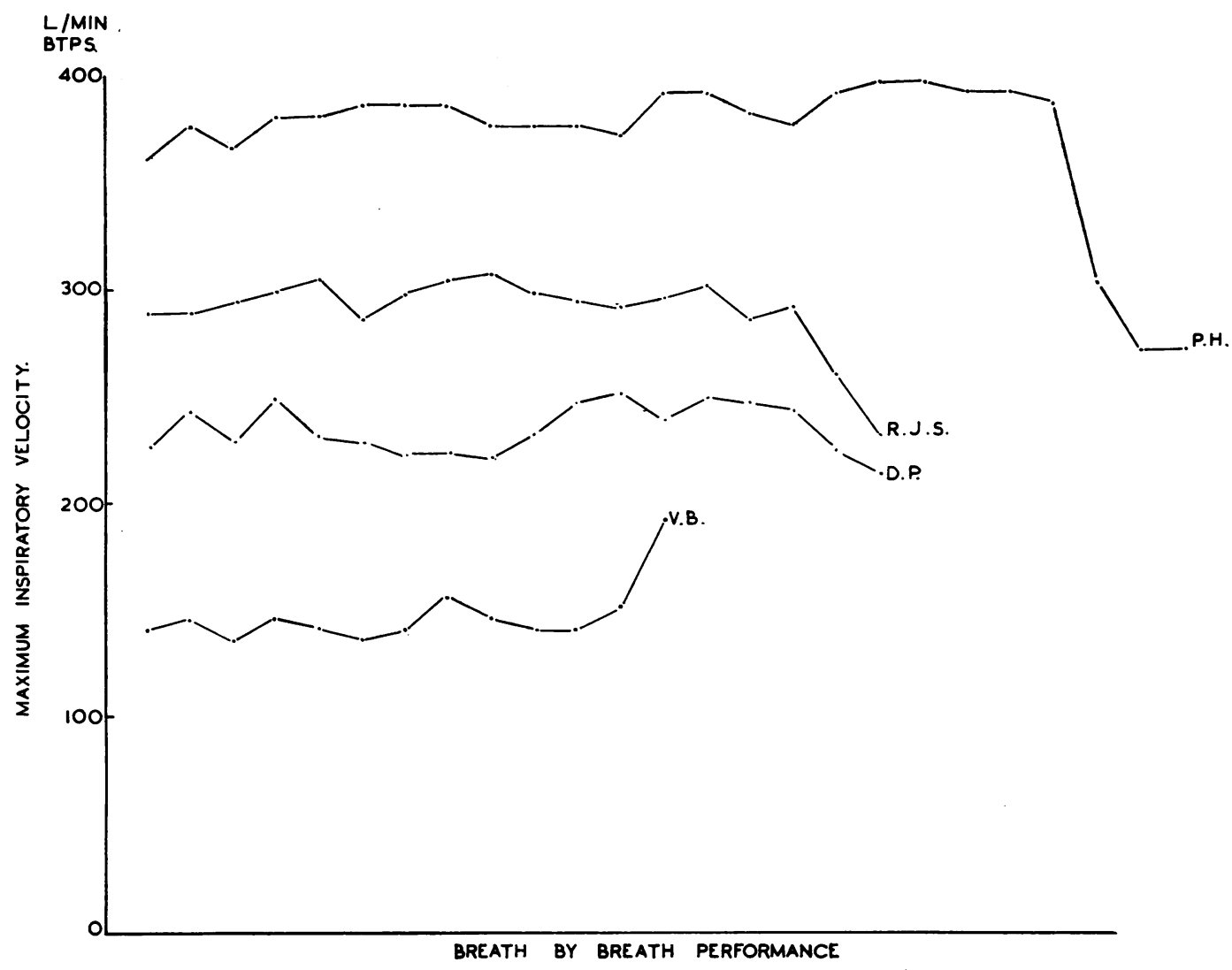

Fig. 4.-Changes of performance during maximum breathing test. Mean curves from each of four subjects to show breathby-breath changes of maximum inspiratory velocity. Note fatigue during last few breaths.

oscillation of the water column. It has been suggested (Bernstein and Kazantzis, 1954) that the optimum rate for the maximum breathing capacity test is in the region of 70 to 80 per min., but although some of the subjects tended to a maximum in this region, D. P. showed little change of M.B.C. over a wide range of respiratory rates, and P. H. (the fittest subject of the group) achieved an excellent breathing capacity at a rate just under 100 per min., while P. B. (the oldest subject, and the least active member of the group) showed an optimum rate of about 60 per min. It seems likely that if pathological subjects were included in the series an even wider range of optimum rates would be obtained, and there thus appears little advantage to be gained from performing the maximum breathing test at a standard rate.

\section{The Fast Vital Capacity}

The pattern of tracing obtained by asking a normal subject to make a rapid expiration or in- spiration into a recording spirometer has been discussed recently by Kennedy (1953) and by Bernstein (1954). The present pneumotachograph system, by virtue of its rapid response and high natural frequency, seemed well suited to a further analysis of this procedure. Accordingly, a number of "fast vital capacity" records (both inspiratory and expiratory) have been obtained from each of the seven subjects. For this purpose a short rubber mouthpiece was connected directly to the pneumotachograph.

Form OF EXPIRATORY Tracing.-Kennedy (1953) pointed out that the fast expiratory tracing obtained with a normal Benedict-Roth spirometer is not uniform. The initial part of the curve is steep and linear; this is succeeded rather abruptly by a second fraction that is less steep, and finally the curve shows a number of undulations. However, it has been shown recently (Bernstein, 1954) that if a light cellulose-acetate spirometer bell is used the expiratory curve assumes a smooth 
exponential form. Bernstein has attributed the irregularities in the earlier tracings to the effect of oscillations in the spirometer water-jacket, and it seems very probable that this is one contributory cause. A number of the present fast expiratory tracings do approximate to the smooth exponential curve described by Bernstein, but this form of tracing is by no means constant (Fig. 5). In some records two distinct maxima of air flow are observed, and in others marked undulations appear in the final part of the tracing. The magnitude of these undulations seems to bear relation to the " noisiness" of expiration, and by deliberately increasing the noise of expiration this feature of the tracing may be markedly accentuated. These observations would therefore suggest that in some subjects a maximal respiratory effort is associated with narrowing of the airway in the laryngeal or pharyngeal region, and the resulting stridor may show itself as undulations in the vital capacity tracing.
The Volume.-It is widely recognized (Cournand and Richards, 1941 ; Mills, 1949 ; Gilson and Hugh-Jones, 1949) that if a subject is allowed to perform the vital capacity test at his own speed there is no systematic difference between the inspiratory and the expiratory capacity. However, the present records give good evidence (Table II) that if the test is performed as rapidly as possible

TABLE II

DIFFERENCE IN YOLUME BETWEEN FAST INSPIRATORY AND FAST EXPIRATORY VITAL CAPACITY

\begin{tabular}{|c|c|c|c|c|c|c|c|}
\hline Subject & $\begin{array}{c}\text { Inspira- } \\
\text { tory } \\
\text { Capacity } \\
\text { (ml. } \\
\text { A.T.P.S.) }\end{array}$ & $\begin{array}{c}\text { Expira- } \\
\text { tory } \\
\text { Capacity } \\
\text { (ml. } \\
\text { A.T.P.S.) }\end{array}$ & $\underset{\text { A.T.P.S. }}{\triangle}$ & $\begin{array}{l}\mathbf{S} \\
\triangle\end{array}$ & $\mathrm{n}$ & $\mathbf{t}$ & $\mathbf{P}$ \\
\hline $\begin{array}{l}\text { R. J.S. } \\
\text { J. E. } \\
\text { D. P. } \\
\text { P. B. } \\
\text { V. B. } \\
\text { M. W. } \\
\text { P. H. }\end{array}$ & $\begin{array}{l}3,794 \\
4,355 \\
2,931 \\
2,923 \\
2,570 \\
4,558 \\
5,207\end{array}$ & $\begin{array}{l}4,719 \\
4,845 \\
3,463 \\
3,498 \\
2,352 \\
5,478 \\
5,642\end{array}$ & $\begin{array}{r}925 \\
490 \\
532 \\
575 \\
-218 \\
920 \\
435\end{array}$ & $\begin{array}{l}244 \\
227 \\
125 \\
176 \\
129 \\
157 \\
110\end{array}$ & $\begin{array}{l}26 \\
10 \\
15 \\
10 \\
10 \\
10 \\
10\end{array}$ & $\begin{array}{l}3.79 \\
2 \cdot 16 \\
4.27 \\
3.27 \\
1.69 \\
5.87 \\
3.95\end{array}$ & $\begin{array}{r}<0.001 \\
0.05-0.10 \\
<0.001 \\
0.01-0.001 \\
0.10-0.20 \\
<0.001 \\
0.001-0.01\end{array}$ \\
\hline
\end{tabular}

there is a significant difference between the measurements, most subjects deve!oping a larger capacity during expiration.

Time TAKen over DeliVERY.-It is recognized (Gilson and Hugh-Jones, 1949) that in normal subjects a minimum period of five seconds is required for expulsion of the entire vital capacity. It can be seen from Table III that if instructed to perform the test "as rapidly as possible" most subjects take considerably less than five seconds, and it is evident that for any given subject the "fast vital capacity" will deviate from the true vital capacity ? by an amount proportional $N$ to the speed of delivery. Further, five of the seven subjects show a highly significant difference of time between inspiration and expiration; this difference seems adequate to account for the greater volume of the fast expiratory capacity noted above.
FIG. 5.-Fast vital capacity tracings obtained by pneumotachograph. Examples of variations in form of tracing obtained from one normal subject (R. J.S.). Note particularly the effect of

" no ise" in increasing undulations of expiratory tracing. (a) EXPONENTIAL FAST EXPIRATORY CAPACITY

(b) "NOISY" EXPIRATION SHOWINC UNDULATIONS

(c) TYPICAL FAST INSPIRATORY CAPACITY

(d) "FAST EXPIRATORY CAPACITY'SHOWINC TWO MAXIMA OF VELOCITY. 
TABLE III

DIFFERENCE IN AVERAGE TIME OCCUPIED BY FAST INSPIRATORY AND FAST EXPIRATORY VITAL CAPACITY

\begin{tabular}{l|c|c|c|c|c|c|c}
\hline Subject & $\begin{array}{c}\text { Inspira- } \\
\text { tion } \\
\text { (sec.) }\end{array}$ & $\begin{array}{c}\text { Expira- } \\
\text { tion } \\
\text { (sec.) }\end{array}$ & $\Delta$ & $\begin{array}{c}\text { S } \\
\Delta\end{array}$ & $\mathbf{n}$ & $\mathbf{t}$ & $\mathbf{P}$ \\
\hline R. J. S. & 1.73 & 4.64 & 2.91 & 0.14 & 26 & 21.4 & $<0.001$ \\
J.E. & 1.80 & 3.29 & 1.49 & 0.21 & 10 & 7.12 & $<0.001$ \\
D.P. & 2.14 & 2.51 & 0.37 & 0.26 & 15 & 1.43 & $0.1-0.2$ \\
P. B. & 1.58 & 3.19 & 1.61 & 0.15 & 10 & 10.4 & $<0.001$ \\
V. B. & 1.95 & 2.20 & 0.25 & 0.20 & 10 & 1.25 & $0.2-0.3$ \\
M. W. & 1.39 & 4.03 & 2.64 & 0.19 & 10 & 14.1 & $<0.001$ \\
P. H. & 1.11 & 3.38 & 2.27 & 0.22 & 10 & 10.5 & $<0.001$ \\
\hline
\end{tabular}

Time Taken to Reach Peak Velocity.-It is not easy to estimate velocity of air-flow from ordinary spirometer records, but if the published tracings of Kennedy (1953) and Bernstein (1954) are compared there appears to be a difference in the time required to reach a peak velocity. In Kennedy's record (Thorax, 8, 73) a maximum velocity appears to be reached in about 0.5 seconds, while the tracings of Bernstein (Thorax, 9, 64) show an almost instantaneous maximum. The pneumotachograph gives more precise information on this point (Table IV), and tends to support the accuracy

TABLE IV

TIME TAKEN TO REACH MAXIMUM VELOCITY DURING FAST VITAL CAPACITY MEASUREMENTS

\begin{tabular}{l|c|c|c|c|c|c|c}
\hline Subject & $\begin{array}{c}\text { Inspira- } \\
\text { tion } \\
\text { (sec.) }\end{array}$ & $\begin{array}{c}\text { Expira- } \\
\text { tion } \\
\text { (sec.) }\end{array}$ & $\Delta$ & S & n & $t$ & P \\
\hline R. J. S. & 0.57 & 0.90 & 0.33 & 0.06 & 12 & 5.48 & $<0.001$ \\
J. E. & 0.92 & 0.80 & -0.12 & 0.09 & 10 & 1.33 & - \\
D. P. & 0.58 & 0.51 & -0.07 & 0.05 & 10 & 1.28 & - \\
P. B. & 0.55 & 0.59 & 0.04 & 0.08 & 10 & 0.50 & - \\
V. B. & 0.53 & 0.84 & 0.31 & 0.11 & 10 & 2.92 & $0.01-0.02$ \\
M. W. & 0.53 & 0.65 & 0.12 & 0.07 & 10 & 1.74 & $0.1-0.2$ \\
P. H. & 0.48 & 0.36 & -0.12 & 0.04 & 10 & 2.93 & $0.01-0.02$ \\
\hline
\end{tabular}

of Kennedy's tracing, since most subjects take about 0.5 seconds to reach a peak velocity during the inspiratory test, and 0.5 seconds or longer during the expiratory test.

The Peak Velocity.-There is considerable personal variation in the peak velocity of air-flow

TABLE V

PEAK VELOCITIES DURING FAST VITAL CAPACITY MEASUREMENTS

\begin{tabular}{|c|c|c|c|c|c|c|c|c|}
\hline $\begin{array}{c}\text { Sub- } \\
\text { ject }\end{array}$ & $\begin{array}{c}\text { Inspira- } \\
\text { tion } \\
\text { (1./min. } \\
\text { B.T.P.S.) }\end{array}$ & $\begin{array}{l}\text { Expira- } \\
\text { tion } \\
\text { (1./min. } \\
\text { B.T.P.S.) }\end{array}$ & $\Delta$ & $\begin{array}{l}\mathbf{S} \\
\Delta\end{array}$ & $\mathbf{n}$ & $\mathbf{t}$ & $\mathbf{P}$ & $\begin{array}{l}\text { M.B.C. } \\
\text { Value } \\
\text { (1.imin. } \\
\text { B.T.P.S.) }\end{array}$ \\
\hline $\begin{array}{l}\text { R. J.S. } \\
\text { J. E. } \\
\text { D. P. } \\
\text { P. B. } \\
\text { V. B. } \\
\text { M. W. W. } \\
\text { P. H. }\end{array}$ & $\begin{array}{l}283 \\
273 \\
203 \\
177 \\
187 \\
315 \\
444\end{array}$ & $\begin{array}{l}183 \\
309 \\
291 \\
264 \\
111 \\
370 \\
427\end{array}$ & \begin{tabular}{|r|}
-100 \\
+37 \\
88 \\
87 \\
-76 \\
55 \\
-18
\end{tabular} & \begin{tabular}{|r|}
24.4 \\
23.8 \\
17.1 \\
25.0 \\
9.9 \\
17.4 \\
26.8
\end{tabular} & $\begin{array}{l}26 \\
10 \\
10 \\
10 \\
10 \\
10 \\
10\end{array}$ & $\begin{array}{l}4 \cdot 10 \\
1.54 \\
5 \cdot 16 \\
3.48 \\
7 \cdot 67 \\
3 \cdot 14 \\
0.65\end{array}$ & $\begin{array}{c}<0.001 \\
<\overline{0.001} \\
0.01-0.0001 \\
<0.001 \\
0.01 \\
-\end{array}$ & $\begin{array}{l}336 \\
380 \\
233 \\
217 \\
179 \\
383 \\
365\end{array}$ \\
\hline
\end{tabular}

during the fast vital capacity test, some subjects developing a higher velocity during inspiration, others during expiration (Table V). Comparison with the average maximum inspiratory velocity during the M.B.C. test shows moderate agreement, although in some subjects the M.B.C. velocities seem rather higher. It is clear that if the M.B.C. and fast vital capacity tracings are to be comparable the "fast vital capacity" test must be performed at least as rapidly as in the present experiments, and the values recorded can never be more than an approximation to the true vital capacity.

\section{Discussion}

The least controversial test of breathing capacity is the 15 -second maximum breathing test, and the present experiments have shown that the pneumotachograph can be modified to give a very satisfactory low resistance system for the measurement of this quantity. However, even normal fit subjects tend to show some fall of maximum respiratory velocity during the last few seconds of the test, and the effects of fatigue will probably be greater in pathological subjects.

The search for a less exhausting method of assessment has centred on the "fast vital capacity" tracings, but these have been considered largely as a means of predicting the maximum breathing capacity. The pneumotachograph permits the accurate measurement of a number of other parameters, including the peak velocity of air-flow, the time required for the delivery of a fast vital capacity sample, and the relative magnitudes of true and fast vital capacity volumes, and it seems possible that these parameters may in the future prove valuable measures of respiratory capacity in their own right.

There is at present disagreement concerning the best method to predict the M.B.C. from the fast vital capacity. Most workers have used some arbitrary fraction of the fast expiratory capacityone second (Tiffeneau, Bousser, and Drutel, 1949 ; Roche and Thivollet, 1949; Gaensler, 1951; Hirdes and van Veen, 1952) or $0.75 \mathrm{sec}$. (Kennedy, 1953). Bernstein and Kazantzis (1954) have pointed out that the fast inspiratory capacity tracing also has a similar form to the M.B.C. record, and this should therefore be used with the fast expiratory record to increase the precision of the predicted M.B.C. These authors have further noted that, as the respiratory rate is increased, inspiration tends to fall short of the full inspiratory capacity during the performance of the M.B.C. test, and it is therefore important to predict the M.B.C. from the middle rather than the initial 
slope of the fast vital capacity curve. The present experiments show clearly that by avoiding the extremes of inspiration and expiration the subject is in fact operating over that range of chest movements at which a maximum air velocity can be developed (Fig. 6), although owing to the shape of the pressure/volume diagram for the human chest (Fenn, 1951) the "swept fraction" of the vital capacity is inevitably a compromise between the optimum for inspiration and the optimum for expiration. It has been shown (Bernstein and Kazantzis, 1954) that the relative duration of the inspiratory phase of respiration increases with the rate at which the M.B.C. test is performed, and the reason for this finding is again apparent from Fig. 6. As the "swept fraction" of the vital capacity decreases, less and less of the exponential tail of the expiratory tracing is ventilated, until a point is reached where the two phases of respiration occupy an equal period of time. In most subjects this occurs at a respiratory rate of about 60 per min., and if the M.B.C. is to be predicted from inspiratory and expiratory curves it seems convenient to predict for this rate. With the pneumotachograph tracings the E.F.R. ${ }^{60}$ and I.F.R. ${ }^{60}$ values can be calculated quite simply by marking off a vertical strip corresponding to 0.5 seconds in the region of maximal velocity of air flow, and measuring this area with a planimeter. There is a slight theoretical error with this technique, since the velocity is a compromise between inspiratory and expiratory optima, but in practice this error is counteracted by the fact that the peak velocity during the M.B.C. test is slightly greater than the peak velocity during the fast vital capacity test.

It can be seen from Table VI that the pooled E.F.R. ${ }^{60}$ and I.F.R. ${ }^{60}$ data show a closer correlation with the M.B.C. than either value taken by itself. However, an equally good correlation is yielded by the pooled E.F.V.C. and I.F.V.C. data. The explanation of this anomaly is to be found in the relative error of the individual measurements. It is well known that the vital capacity is a relatively stable quantity in any one individual, the standard deviation of a single measurement usually being less than $5 \%$ (Gilson

TABLE VI

CORRELATION OF M.B.C. (PNEUMOTACHOGRAPH) WITH I.F.R.60, E.F.R 60 AND VITAL CAPACITY (MEAN OF FAST INSPIRATORY 'AND FAST EXPIRATORY CAPACITIES)

\begin{tabular}{|c|c|c|c|c|c|}
\hline Subject & $\begin{array}{c}\text { Mean } \\
\text { M.B.C. } \\
\text { (1./min. } \\
\text { B.T.P.S.) }\end{array}$ & $\begin{array}{l}\text { Mean } \\
\text { I.F.R. }{ }^{60} \\
\text { (1./min. } \\
\text { B.T.P.S.) }\end{array}$ & $\begin{array}{l}\text { Mean } \\
\text { E.F.R. }{ }^{60} \\
\text { (1./min. } \\
\text { B.T.P.S.) }\end{array}$ & $\begin{array}{c}\text { Mean E } \\
\text { andI.F.R.60 } \\
\text { (l./min. } \\
\text { B.T.P.S.) }\end{array}$ & $\begin{array}{c}\text { Mean } \\
\text { Vital } \\
\text { Capacity } \\
\text { (ml. } \\
\text { A.T.P.S.) }\end{array}$ \\
\hline $\begin{array}{l}\text { R. J. S. } \\
\text { J. E. } \\
\text { D. P. } \\
\text { P. B. } \\
\text { v. B. } \\
\text { M. W. } \\
\text { P. H. }\end{array}$ & $\begin{array}{r}143.5 \\
166.0 \\
111.0 \\
102.0 \\
75.9 \\
152.0 \\
184.0\end{array}$ & $\begin{array}{r}140.1 \\
142.5 \\
91.3 \\
90.7 \\
87.1 \\
170.3 \\
169.2\end{array}$ & $\begin{array}{r}108.1 \\
141.0 \\
132.0 \\
119.3 \\
54.2 \\
180.5 \\
213.2\end{array}$ & $\begin{array}{r}124.1 \\
141.8 \\
111.7 \\
105.0 \\
70.7 \\
175.4 \\
191.2\end{array}$ & $\begin{array}{l}4,257 \\
4,600 \\
3,119 \\
3,211 \\
2,479 \\
5,018 \\
5,424\end{array}$ \\
\hline & $\begin{array}{l}\text { Correlation } \\
\text { coefficient }\end{array}$ & $r=0.915$ & $r=0.842$ & $r=0.923$ & $r=0.932$ \\
\hline
\end{tabular}

and Hugh Jones, 1949 ; Mills, 1949 ; Rahn, Fenn, and Otis 1948). The standard deviation of the "fast vital capacity" is perhaps a little greater, particularly with the fast inspiratory readings, but is still under $10 \%$ (Fig. 7). On the other hand the I.F.R. and E.F.R. ${ }^{60}$ values show a standard deviation of about $20 \%$. This large error does not appear related to the difficulties of measuring a 


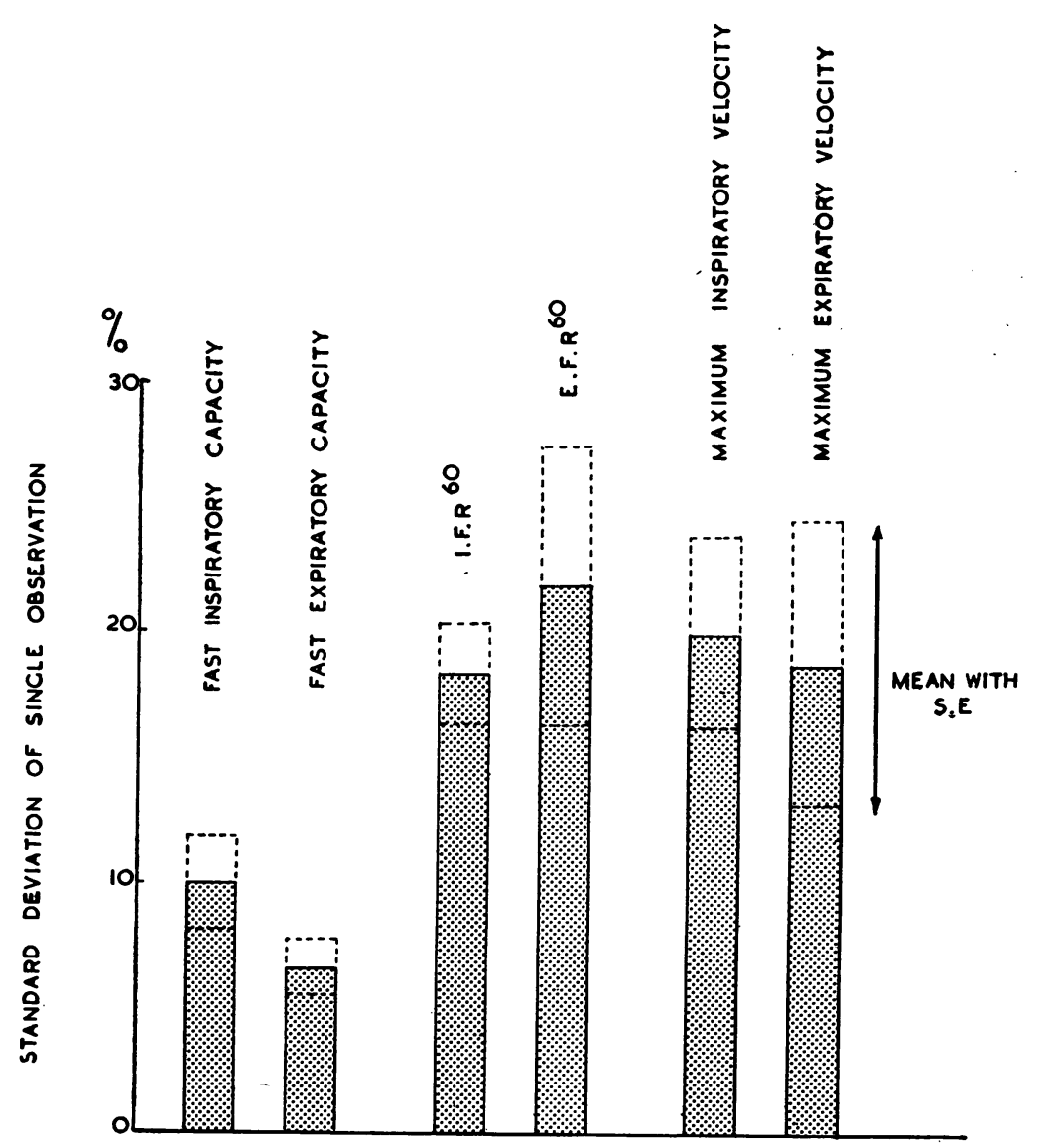

FIG. 7.-Mean values for standard deviation of single observations of fast vital capacity readings. I.F.R. and E.F.R. ${ }^{60}$, and maximum inspiratory and expiratory velocity. Data from seven normal subjects.

small area with the planimeter, since the peak velocity (which is easily measured) shows a similar variability. It seems merely that when asked to deliver a vital capacity sample as rapidly as possible, subjects do so with a variable peak speed. The implication of this finding is that the theoretical advantage of predicting the M.B.C. from a fraction of the fast vital capacity tracing is outweighed by lack of repeatability in the measurement, and it is therefore preferable to make the prediction from the entire fast vital capacity.

\section{SUMMARY}

The physical characteristics of a pneumotachograph system suited to the investigation of breathing capacity are described. A trial of the apparatus on seven normal subjects has yielded M.B.C. values similar to those previously reported for low resistance systems.
The sensitive recording system has allowed further investigation of the theoretical background of the M.B.C. and "fast vital capacity" tests. There is a wide personal variation in the optimum respiratory rate for the performance of the M.B.C. test, and most subjects show some decline of maximum inspiratory velocity during the last few seconds of the test.

The " fast vital capacity" tracings do not always conform to smooth exponential curves. Owing to the speed of delivery the volume delivered is less than the true vital capacity, particularly during inspiration. Although theoretical grounds suggest the prediction of the M.B.C. from a 30-second fraction of the vital capacity tracing, in practice a better correlation is obtained from the entire fast inspiratory and expiratory vital capacity curves. This anomaly appears related to the considerable variations of peak gas velocity during the performance of fast vital capacity tests. 


\section{REFERENCES}

Baldwin, E. deF., Cournand, A., and Richards, D. W. (1948). Medicine, Baltimore, 27, 243.

Bernstein, L. (1954). Thorax, 9, 63.

— and Kazantzis, G. (1954). Ibid., 9, 326

- D'Silva, J. L., and Mendel, D. (1952). Ibid., 7, 255.

Cournand, A., and Richards, D. W. (1941). Amer. Rev. Tuberc., 44, 123.

Fenn, W. O. (1951). Amer. Forces Tech. Rep. 6528, 156.

Gaensler, E. A. (1951). Amer. Rev. Tuberc., 64, 256.

Gilson, J. C., and Hugh-Jones, P. (1949). Clin. Sci., 7, 185.

Gray, J. S., Barnum, D. R., Matheson, H. W., and Spies, S. N. (1950). J. clin. Invest., 29, 677.

Greifenstein, F. E., King, R. M., Latch, S. S., and Comroe, J. H. (1952). J. appl. Physiol., 4, 641.

Hermannsen, J. (1933). Z. ges. exp. Med., 90, 130.
Hirdes, J. J., and Veen, G. van (1952). Acta tuberc. scand., 26, 264.

Kennedy, M. C. S. (1953). Thorax, 8, 73.

McKerrow, C. B. (1953a). J. Physiol., Lond., 122, 3 P. (1953b). Quoted from Cotes, J. E., Proc. roy. Soc. B (1954), 143, 38.

Mills, J. N. (1949). J. Physiol., Lond., 110, 76, 207.

Rahn, H., Fenn, W. O., and Otis, A. B. (1949). J. appl. Physiol., 1, 725.

Roche, L., and Thivollet, J. (1949). Arch. Mal. prof., 10, 448.

Silverman, L., and Whittenberger, J. L. (1950). Meth. med. Res., 2, 104.

Tiffeneau, R., Bousser, J., and Drutel, P. (1949). Paris méd. (partie méd.), 39, 543.

Turner, J. A., and McLean, R. L. (1951). Pediatrics, 7, 360.

Wright, G. W., Yee, L. B., Filley, G. F., and Stranahan, A. (1949). J. thorac. Surg., 18, 372. 